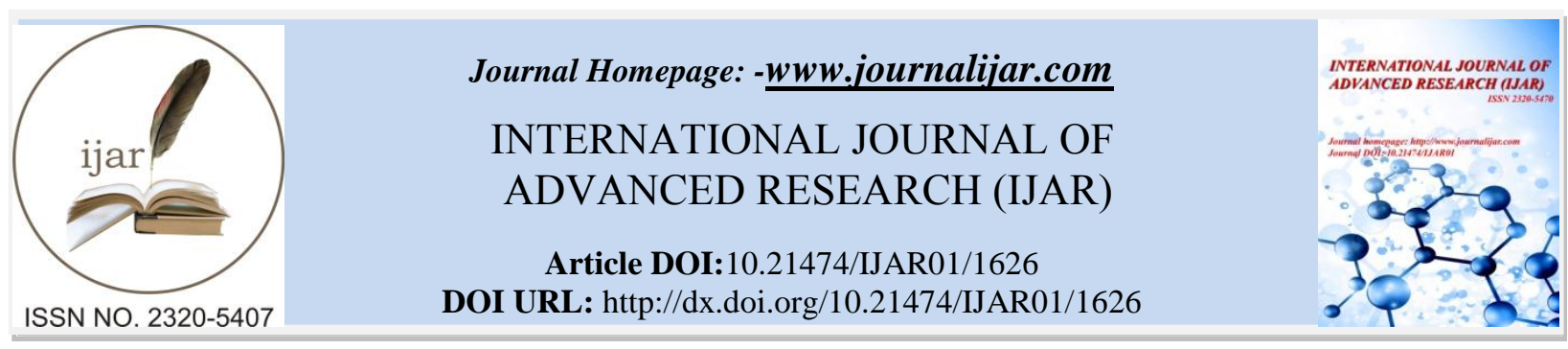

RESEARCH ARTICLE

\title{
WILL RESIN INFILTRATION WITH ICON PREVENT ENAMEL DEMINERALIZATION AROUND ORTHODONTIC BRACKETS?
}

Omnia A. Elhiny ${ }^{1}$ and Ghada A. Salem ${ }^{2}$.

1. Orthodontics researcher, Department of Orthodontics and Pediatric Dentistry, National research center.

2. Pedodontics lecturer, Department of Orthodontics and Pedodontics, Fayoum University.

\section{Manuscript Info}

\section{Manuscript History}

Received: 13 July 2016

Final Accepted: 17 August 2016

Published: September 2016

Key words:-

Demineralization, orthodontic brackets, ICON Resin infiltrant, shear bond strength, surface microhardness.

\begin{abstract}
Objective:The aim of this study was to investigate the ability of Icon surface pretreatment to prevent demineralization under and around orthodontic brackets and its subsequent effect on the shear bond strength. Methods: A total number of 20 sound human maxillary premolars freshly extracted for orthodontic treatment were divided into two groups. Group one: control group with no surface pretreatment. Group two: ICON surface pretreatment was done for the enamel surface before bonding the brackets. Both groups were subjected to a 21-day pH-cycling protocol. Shear bond strength measured in mega Pascal (MPa) and surface microhardness measured in Vickers hardness value (HV) were evaluated after thermo-cycling and statistically analyzed. Adhesive remnants index (ARI) scores were determined at 25x magnification and statistically analyzed. Results: there was no significant difference in surface hardness within the study groups; before and after $\mathrm{pH}$ cycling as well as no significant difference in shear bond strength in the ICON surface pretreatment group when compared to the control group. Conclusion:ICON surface pretreatment for prevention of white spot lesions can be done clinically under orthodontic brackets without affecting the shear bond strength significantly.
\end{abstract}

\section{Introduction:-}

Dental caries is one of the most prevalent diseases. Understanding the caries process is highly important to establish a proper treatment plan for each patient. Dental caries is a dynamic process involving periods of demineralization and remineralization. During the demineralization period there is a dissolution of calcium hydroxyl apatite from the enamel and the production of micro-porosities that result in development of enamel subsurface caries lesions which appear clinically as chalky white and rough patches on the enamel surface denoting active lesions or bright white and smooth spots on the demineralized enamel surface representing inactive lesions. These initial carious lesions can be called white-spot lesions ${ }^{1,2}$.

Corresponding Author: Omnia A. Elhiny

Address: - Orthodontics researcher, Department of Orthodontics and Pediatric Dentistry, National 1661 research center. 
During orthodontic treatment, white spot lesions are the most common problem which might also be present at the start of treatment in high soft- drink consumers ${ }^{3}$. It results from enamel demineralization around the brackets as the brackets create retentive areas for plaque and bacterial accumulation that leads to a decrease in pH and dissociation of calcium and phosphate ions from enamel denoting the first sign of caries formation ${ }^{4}$.

Treatment of white spot lesions is based mainly on inhibiting demineralization and enhancing remineralization processes. This can be achieved by; either remineralization of the enamel surface using fluoride or calcium phosphate products that result in increasing calcium and phosphate ions and preventing further demineralization of the enamel surface, or by sealing the enamel surface with a low-viscosity resin (Icon caries infiltrant, DMG) with its high penetration ability that creates a caries-protective shield or a barrier that helps in strengthening the enamel surface and preventing caries progression ${ }^{2}$.

Debonding of orthodontic brackets occurs when the brackets are subjected to mechanical and thermal stresses; this takes place either after a short time from bonding the brackets or at the late stages of orthodontic treatment ${ }^{5}$. Achieving a strong, durable and reliable adhesive bond between the orthodontic bracket and the tooth enamel is mandatory for a successful orthodontic treatment ${ }^{6,7}$.

Accordingly, the aim of this study was to investigate the ability of ICON surface pretreatment to prevent demineralization under and around orthodontic brackets and its subsequent effect on the shear bond strength.

\section{Materials and Methods: -}

The materials used in this study were ICON - Smooth Surface resin infiltrant (DMG, Germany) and Transbond XT(3M Unitek, USA). The compositions and instructions for these materials were shown in Table (1).

\section{Selection of teeth:-}

A total number of 20 sound human maxillary premolars, freshly extracted for orthodontic treatment were used in this study. The teeth were examined under digital microscope to be free from decay, hypoplastic defects, cracks or restorations. Scaling and polishing were performed on all teeth in order to remove any plaque, calculus or attached periodontal tissue, then teeth included in this study were stored in $0.025 \%$ thymol solution until used.

\section{Specimen preparation:-}

The specimens were embedded in self-cure acrylic resin, such that the buccal surface of the crown was projected out of acrylic surface in order to allow proper bonding and measuring procedures

\section{Grouping of specimens:-}

The specimens were equally and randomly divided, by a participant in the research other than the one conducting it, into two groups. The specimens were put in dark, opaque and sealed envelopes and sequentially numbered, for the sake of allocation concealment; the envelopes were then divided into two groups; 10 in each group, according to a computer -generated randomization list (Random sequence generator; www.random.org).

Group one: (control group with no surface pretreatment) the enamel was etched with $37 \%$ phosphoric acid then Transbond XT primer was applied followed by Transbond XT adhesive. Group two: (ICON surface pretreatment group) etching the enamel was done using ICON-Etch 15\% HCL gel. ICON Infiltrant resin was then applied followed by Transbond XT primer. Finally, Transbond XT adhesive was applied.

Ethical approval from the National Research Centre, Medical Research Ethics Committee, registration number 16027.

\section{Application of ICON Infiltrant resin:-}

The material was applied, according to manufacturer instructions, in the center of the enamel surface and $0.5 \mathrm{~mm}$ more around the bracket area to be bonded:

$\checkmark \quad$ ICON-Etch: ICON-Etch was applied onto the enamel surface with periodical massaging of the etching gel over a 2-minute period, then the etching gel was rinsed off with water for at least $30 \mathrm{sec}$.

$\checkmark$ Icon-Dry: the etched enamel surface was dried with oil-free air then ICON-Dry was applied onto the enamel surface and allowed to set for $30 \mathrm{sec}$. 
$\checkmark \quad$ ICON-infiltrant resin: ICON-Infiltrant was applied for 3 minutes to allow it to penetrate into the etched, dried enamel with slight massaging with the applicator to enhance resin infiltration. Then, the Icon-Infiltrant was light cured for 40 seconds after which a second layer of the infiltrant was applied followed by light curing for 40 second after 1 minute from the application.

Application of Transbond XT and bonding the orthodontic brackets:-

$37 \%$ phosphoric acid gel(3M ESPE, St. Paul, MN, USA) was applied on the center of the enamel surface for 30 seconds then rinsed off with water for 15 seconds and dried with oil-free air for 10 seconds until the etched enamel showed a frosty white appearance. After that, Transbond XT primer(3M Unitek, Monrovia, CA, USA) was applied on the etched enamel surface followed by the application of Transbond XT adhesive on both the primed enamel surface and the base of the bracket $\{0.22(0,56 \mathrm{~mm})$ Roth $\mathrm{Rx}, 3 \mathrm{M}$ Gemini metal brackets $\}$, then the bracket was placed in the center of the crown along the long axis of the tooth and under hand pressure. Excess resin was removed with an explorer and light curing for 40 seconds was done; divided into 10 seconds each from the mesial, distal, incisal and cervical sides.

\section{pH cycling protocol:-}

The daily $\mathrm{pH}$ cycling procedure included a demineralization period of 6 hours and a remineralization period of 18 hours. The specimens were immersed in $40 \mathrm{~mL}$ of demineralization solution containing calcium $(2 \mathrm{mmol} / \mathrm{L})$, phosphate $(2 \mathrm{mmol} / \mathrm{L})$, and acetate $(75 \mathrm{mmol} / \mathrm{L})$ at $\mathrm{pH}=4.3$ for 6 hours at $37^{\circ} \mathrm{C}$; after the demineralization period, the specimens were rinsed with deionized water then immersed in $20 \mathrm{ml}$ of the remineralizing solution at $37^{\circ} \mathrm{C}$ for 18 hours to simulate the remineralization stage of the caries process. The remineralizing solution consisted of calcium $(1.5 \mathrm{mmol} / \mathrm{L})$, phosphate $(0.9 \mathrm{mmol} / \mathrm{L})$, potassium chloride $(150 \mathrm{mmol} / \mathrm{L})$, and cacodylate buffer $(20 \mathrm{mmol} / \mathrm{L})$ at $\mathrm{pH}=7$. This cycling procedure was repeated daily for 21 days ${ }^{8}$.

\section{Microhardness test:-}

The microhardness was measured two times before any treatment of the enamel surface as baseline control, then after $\mathrm{pH}$ cycling and debonding of brackets. Surface Micro-hardness of the specimens was determined using Digital Display Vickers Micro-hardness Tester (Model HVS-50, Laizhou Huayin Testing Instrument Co., Ltd. China) with a Vickers diamond indenter. For all the specimens a magnification of $40 \mathrm{X}$ was used, and a load of $1 \mathrm{Kg}$ was applied to the surface of the specimens for 20 seconds where three indentations were made in each specimen ${ }^{1}$.

\section{Shear Bond Strength test:-}

Shear Bond Strength was measured after $\mathrm{pH}$ cycling and before measuring the surface hardness for the second time. Specimens in acrylic blocks were mounted vertically at the universal testing machine(Model LRX-plus; Lloyd Instruments Ltd., Fareham, UK) and a stainless steel rod with a chisel edge was used to apply a vertical force of $5 \mathrm{KN}$ in occluso-gingival direction with crosshead speed of $0.5 \mathrm{~mm} / \mathrm{min}$ until failure and debonding of the brackets. The data was recorded using computer software(Nexygen-MT; Lloyd Instruments). The shear strength values were then calculated according to the following equation ${ }^{6}$ :

Shear bond strength = load at failure/surface area of bracket

\section{Results:-}

Surface micro-hardness results:-

Surface micro-hardness results measured in Vickers hardness value (HV) for both groups as a function of $\mathrm{pH}$ cycling were presented in table (2).

At baseline when the two groups were compared, it was found that group one (control group) recorded higher Vickers hardness mean value, $(295.6667 \pm 31.56 \mathrm{HV})$, than group two (ICON surface pretreatment group); 264.2 $\pm 42.64 \mathrm{HV}$. The difference between both groups was statistically non-significant as indicated by un-paired ttest; $(\mathrm{p}=0.0891>0.05)$. After $\mathrm{pH}$ cycling, it was found that group one recorded higher Vickers hardness mean value, $(281.22 \pm 36.79 \mathrm{HV})$, than group two; $(259.03 \pm 22.2 \mathrm{HV})$. The difference between both groups was statistically insignificant as indicated by un-paired t-test; $(\mathrm{p}=0.1608>0.05)$.

On comparing each group to itself both at baseline and after $\mathrm{pH}$ cycling, it was found that in group one there was a higher Vickers hardness mean value, $(295.6667 \pm 31.56 \mathrm{HV})$, before than after pH cycling $(281.22 \pm 36.79 \mathrm{HV})$. However, the difference was statistically insignificant as indicated by un-paired t-test; $(\mathrm{p}=0.42346>0.05)$. Similarly, 
in group two there was a higher Vickers hardness mean value, $(264.2 \pm 42.64 \mathrm{HV})$, before than after pH cycling; $(259.03 \pm 22.2 \mathrm{HV})$. The difference was statistically insignificant as indicated by un-paired $t$-test $(\mathrm{p}=0.7729>0.05)$.

\section{Bracket Shear bond strength results:-}

Descriptive statistics of the shear bond strength results measured in mega Pascal (MPa) for both groups were presented graphically drawn in figure (1)

It was found that for group one the mean \pm SD values were $(15.28013 \pm 3.41223 \mathrm{MPa})$ with a minimum value 11.40743MPa and a maximum value 19.16597 MPa, while for group two the mean \pm SD values were (11.97111 \pm $3.137522 \mathrm{MPa}$ ) with minimum value $7.930453 \mathrm{MPa}$ and maximum value $15.06545 \mathrm{MPa}$.

Generally, all groups showed clinically acceptable mean bond strengths (> $6 \mathrm{MPa}$ ). Group one recorded a higher shear bond strength mean value, $(15.28013 \pm 3.41223 \mathrm{MPa})$, than group two; $(11.97111 \pm 3.13752 \mathrm{MPa})$. The difference between both groups was statistically insignificant as indicated by student $t$-test $(\mathrm{p}=0.1491>0.05)$.

\section{Failure mode distribution:-}

After debonding, all teeth and brackets in the testgroups were viewed using a light stereomicroscope (Olympus SZ 6045 TR Zoom stereomicroscope, OlympusOptical Co, Osaka, Japan) at $\times 25$ magnification todetermine the bracket failure interface (figure 2). Any adhesiveremaining after debonding was assessed and scoredaccording to the modified adhesive remnant index (ARI;Olsen et al) ${ }^{9}$.

The scoring criteria of the index were asfollows:

Score $1=$ all of the composite, with an impression ofthe bracket base remains on the tooth; Score $2=$ more than 90per cent of the composite remains on the tooth; Score $3=$ morethan 10 per cent but less than 90 per cent of the compositeremains on the tooth; Score $4=$ less than 10 per cent of compositeremains on the tooth; and Score $5=$ no composite remains onthe tooth.

The frequency distribution of the ARI scores and the chi square comparison of the groups were presented in Table (3). It was found that group one showed predominantly score 3 and score 5 failure mode ( $40 \%$ for each) while score 4 was $20 \%$ with no record for scores 1 or 2 failure modes. On the other hand, group two showed predominantly score 4 failure mode (40\%) followed by score 2, score 3 and score 5 (20\% for each score) with no record for score 1 failure mode. The difference between failure modes between groups was statistically insignificant as indicated by Chi square test $(\mathrm{P}>0.05)$.

\section{Discussion:-}

The prevalence of white spot lesions (WSLs) at the end of orthodontic treatment may range from $50 \%$ to $97 \%^{10,11}$. However, it was reported previously that WSLs can develop within 1 month of bonding ${ }^{12}$ and not just at the end of treatment. Tufekci et al ${ }^{13}$ reported an $11 \%$ increase in the number of WSLs during the first 6 months of treatment and recommended implementing extra measures to prevent demineralization, if necessary.

Resin infiltration was considered a major breakthrough in micro-invasive technology that would fill, reinforce, and stabilize demineralized enamel. In addition, resin infiltrated lesions showed reduced progression of caries compared to untreated controls ${ }^{14}$.

In this study, two types of tests were used; surface micro-hardness and shear bond strength. Regarding surface micro-hardness, Vickers hardness values for sound enamel were used as reported in previous studies ${ }^{15}$, 16 .The results showed that after $\mathrm{pH}$ cycling there was no statistically significant difference in micro-hardness between the ICON surface pretreatment and the control groups which was in accordance with Burgess and Cakir ${ }^{17}$, and Mugisa ${ }^{18}$. Nadia et al in $2012^{19}$ reported that ICON surface pretreatment sealed the enamel porosities in the infiltrated enamel and, hence the resulted absence of an increase in the surface hardness compared to sound enamel.

On the other hand, studies done by Mugisa ${ }^{18,}$ Meyer and Paris ${ }^{20}$, and Torres ${ }^{21}$ demonstrated that the ICON infiltrant had improved the microhardness readings. This, however, occurred in artificially demineralized lesions where the demineralization was done prior to the infiltration so the microhardness values were compared to originally reduced values.

Regarding shear bond strength, Orthodontic brackets' bond strength normally falls within the range of 4 to 8 $\mathrm{MPa}^{22,23}$, it was also proposed that 5 to $10 \mathrm{MPa}$ was appropriate for bracket fixation ${ }^{24}$. In the current study, the 
ICON surface pretreatment group showed a mean bond strength of $>6 \mathrm{MPa}$. This was in agreement with Naidu et $\mathrm{al}^{25}$, Wiegand et $\mathrm{al}^{26}$ and Tang ${ }^{27}$ who stated that preconditioning sound enamel with the ICON infiltrant system did not impair the shear bond strength of most orthodontic resin cements.

Nevertheless, the control group recorded a statistically insignificant higher shear bond strength which was coincident with the findings of Wiegand ${ }^{26}$. Furthermore, Jia L ${ }^{28}$ explained the lower bond strength in the Icon infiltrated group as possibly due to the polymerization shrinkage and stress of the resin which might increase the risk of leakage, and thus might affect the bond strength. On the other hand,Mews ${ }^{29}$ reported lower bond strength on using the ICON infilterant per see without the conventional primer-adhesive system.

Failure within the bracket-resin-enamel complex could be either an adhesive failure; between the bracket and the resin, or between the tooth surface and the resin. It could also be a cohesive failure within the resin itself ${ }^{6}$. The ARI scores with and without ICON infiltrant preconditioning were not significantly different, in this study, indicating that the amount of residual resin to be removed at debonding was not affected by the presence of the infiltrant ${ }^{25}$. This could be due to the fact that both the composite bonding material and the ICON infiltrant are resin materials.

\section{Conclusion:-}

ICON surface pretreatment for prevention of white spot lesions can be done clinically under orthodontic brackets without affecting the shear bond strength significantly.

\section{Recommendations:-}

Further studies employing microscopic surface examination are needed to further investigate the preventive properties of ICON surface pretreatment.

\section{Acknowledgement:-}

The authors would like to thank Prof. Dr. Mona Ismail Riad for her continuous support and guidance.

Table (1):-material type, composition, manufacturer company and lot number

\begin{tabular}{|c|c|c|c|c|}
\hline Material & Type & Composition & Company & $\begin{array}{l}\text { Lot } \\
\text { number }\end{array}$ \\
\hline \multirow[t]{3}{*}{ Transbond XT } & Acid etch & $37 \%$ orthophosphoric acid $\mathrm{H}_{3} \mathrm{PO}_{4}$ & \multirow{3}{*}{$\begin{array}{l}\text { 3M Unitek, } \\
\text { Monrovia, } \\
\text { USA }\end{array}$} & \multirow[t]{3}{*}{290791} \\
\hline & $\begin{array}{l}\text { Transbond XT } \\
\text { primer }\end{array}$ & $\begin{array}{l}\text { bis-GMA } 45-55 \% \\
\text { TEGDMA } 45-55 \% \\
\text { 4-dimethylaminobenzene ethanol }<0.5 \% \\
\text { camphorquinone }<0.3 \% \\
\text { hydroquinone }<0.03 \%\end{array}$ & & \\
\hline & $\begin{array}{l}\text { Transbond XT } \\
\text { ahesive }\end{array}$ & $\begin{array}{l}\text { luting material: Bis-GMA, bis-EMA, } \\
\text { acrylate, monomers, filler }\end{array}$ & & \\
\hline \multirow[t]{3}{*}{$\begin{array}{ll}\text { Icon } & \text { smooth } \\
\text { surface } & \end{array}$} & Icon-Etch & $\begin{array}{l}15 \% \text { Hydrochloric acid, pyrogenic silicic } \\
\text { acid, surface-active substances }\end{array}$ & \multirow{3}{*}{$\begin{array}{l}\text { DMG, } \\
\text { Hamburg, } \\
\text { Germany }\end{array}$} & \multirow[t]{3}{*}{634902} \\
\hline & Icon-Dry & $99 \%$ ethano & & \\
\hline & Icon-Infiltrant & $\begin{array}{l}\text { TEGDMA based resin matrix,Initiators, } \\
\text { additives }\end{array}$ & & \\
\hline
\end{tabular}

Table (2):-Comparison ofVickers hardness results (Mean \pm SD) for both groups as function of $\mathrm{pH}$ cycling

\begin{tabular}{|l|l|l|l|}
\hline Variables & Before $\boldsymbol{p H}$ cycling & pH cycled & t-test $(\boldsymbol{p}$ value $)$ \\
\hline Group one (Control) & $295.67 \pm 31.56$ & $281.22 \pm 36.79$ & $0.42346 \mathrm{~ns}$ \\
\hline Group two & $264.2 \pm 42.64$ & $259.03 \pm 22.2$ & $0.7729 \mathrm{~ns}$ \\
\hline $\boldsymbol{t}$-test $(\boldsymbol{p}$ value) & $0.0891 \mathrm{~ns}$ & $0.1608 \mathrm{~ns}$ & \\
\hline
\end{tabular}

ns; non-significant $(\mathrm{p}>0.05) \quad * ;$ significant $(\mathrm{p}<0.05)$


Table (3):- Frequency distribution (\%) of the adhesive remnant index(ARI) scores for both groups

\begin{tabular}{|l|l|l|}
\hline \multirow{2}{*}{ Score 1 } & ARI score & Group two \\
\cline { 2 - 3 } & Group one (control) & 0 \\
\hline Score 2 & 0 & 20 \\
\hline Score 3 & 0 & 20 \\
\hline Score 4 & 40 & 40 \\
\hline Score 5 & 20 & 20 \\
\hline Chi square (p value) & 40 & $0.5724 \mathrm{~ns}$ \\
\hline
\end{tabular}

ns; non-significant $(\mathrm{p}>0.05) \quad * ;$ significant $(\mathrm{p}<0.05)$

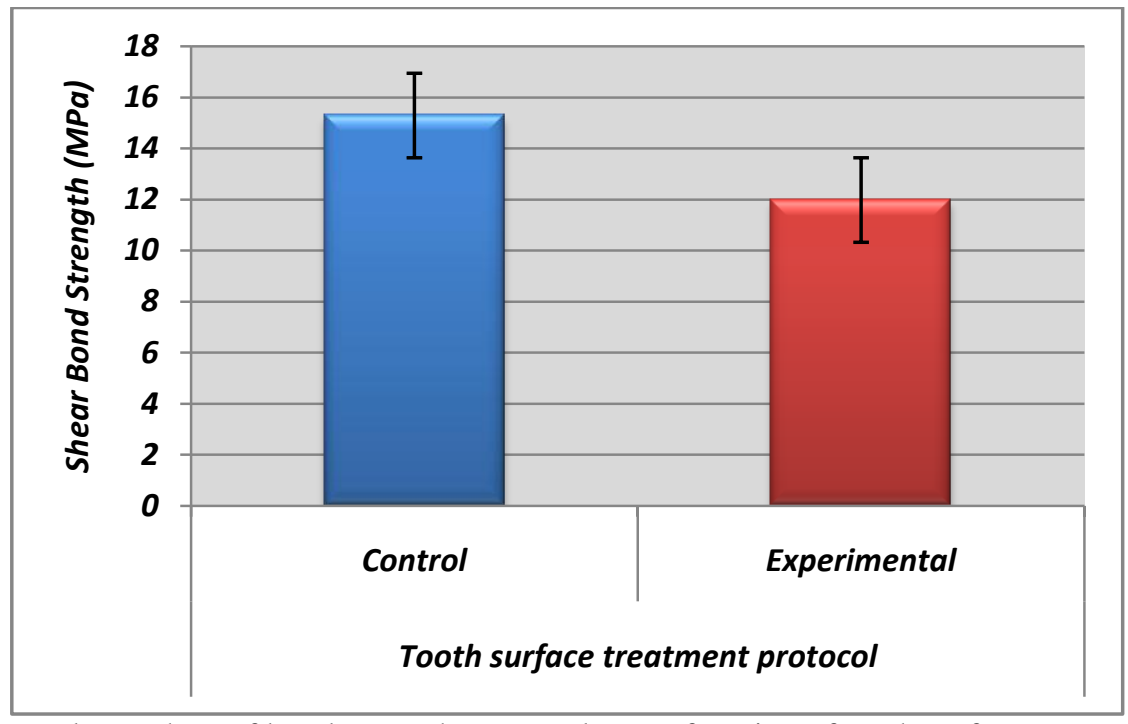

Figure (1):-a column chart of bond strength mean values as function of tooth surface treatment protocol
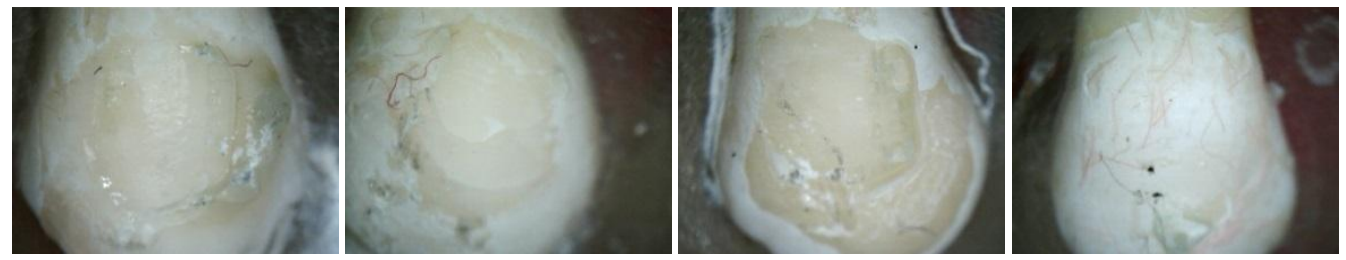

Figure (2):- Representative microscopic image showing mode of failure scores 2,3,4,5respectively

\section{References:-}

1. Taher NM, Alkhamis HA, Dowaidi SMl (2012): The influence of resin infiltration system on enamel microhardness and surface roughness: An in vitro study. The Saudi Dental Journal, 24: 79-84.

2. Torres CRG, Borges AB, Torres LMS, Gomes IS, de Oliveira RSe (2011): Effect of caries infiltration technique and fluoride therapy on the colour masking of white spot lesions. Journal of Dentistry, 39: 202-207.

3. Hammad SM, Enan ET (2013): In vivo effects of two acidic soft drinks on shear bond strength of metal orthodontic brackets with and without resin infiltration treatment. The Angle Orthodontist, 83:648-652.

4. Yetkiner E, Wegehaupt FJ, Attin R, Attin T (2013): Caries infiltrant combined with conventional adhesives for sealing sound enamel in vitro. The Angle Orthodontist, 83: 858-863.

5. Attin R, Stawarczyk B, Kecik D, Knosel M, Wiechmann D, Attin T (2011): Shear bond strength of brackets to demineralize enamel after different pretreatment methods. The Angle Orthodontist, 82: 56-61.

6. Ekizer A, Zorba YO, Uysal T, Ayrikcila S (2012): Effects of demineralizaton-inhibition procedures on the bond strength of brackets bonded to demineralized enamel surface. The Korean Journal of Orthodontics, 42: 17-22.

7. Wiegand A, Stawarczyk B, Kolakovic M, Hlammerle CHF, Attin T, Schmidlin PR (2011): Adhesive performance of a caries infiltrant on sound and demineralised enamel. Journal of Dentistry, 39: 117-121. 
8. Hu W, Featherstone JDB (2005): Prevention of enamel demineralization: An in-vitro study using light-cured filled sealant. American Journal of Orthodontics and Dentofacial Orthopedics, 128: 592-600.

9. Olsen M., Bishara S., Damon P, Jakobsen J R (1997): Evaluation of Scotchbond Multipurpose and maleic acid as alternative methods of bonding orthodontic brackets. American Journal of Orthodontics and Dentofacial Orthopedics, 111: 498-501

10. Gorelick L, Geiger AM, Gwinnet AJ (1982): Incidence of white spot formation after bonding and banding. Am J Orthod., 81:93-98.

11. Boersma JG, van der Veen MH, Lagerweij MD, Bokhout B (2005): Caries prevalence measured with QLF after treatment with fixed orthodontic appliances: influencing factors. Caries Res., 39:41-47.

12. Øgaard B (2008): White spot lesions during orthodontic treatment: mechanisms and fluoride preventive aspects. Semin Orthod., 14:183-193.

13. Tufekci E, Dixon JS, Gunsolley JC, Lindauer SJ (2011): Prevalence of white spot lesions during orthodontic treatment with fixed appliances. Angle Orthod., 81:206-210.

14. Paris S, Meyer-Lueckel H (2010): Inhibition of caries progression by resin infiltration in situ. Caries Res., 44:47-54.

15. Schmitt L, Lurtz C, Behrend D and Schmitz KP (2008 November): Registered Microhardness of human teeth parts and dental filling composites. 4th European Conference of the International Federation for Medical and Biological Engineering (ECIFMBE), 23-27.

16. Borges AB, Yui KCK, D'Avila TC, Takahashi CL, Torres CRG, Borges ALS (2010): Influence of Remineralizing Gels on Bleached Enamel Microhardness in Different Time Intervals. Operative Dentistry, 35(2) : 180-186.

17. Burgess J.O. and Cakir D (2009): Surface Roughness Determination of a Caries Infiltrant Resin. Data on file. DMG, Hamburg, Germany.

18. MUGISA I S (2010): Microhardnes and caries resistance of an infiltrant resin in a novel artificial mouth. Master Thesis Submitted to the graduate faculty of The University of Alabama at Birmingham.

19. Nadia MT, Haifa AA and Sarah MD (2012): The influence of resin infiltration system on enamel microhardness and surface roughness: An in vitro study. The Saudi Dental Journal, 24: 79-84.

20. Meyer L H and Paris S (2008): Progression of artificial enamel caries lesions after infiltration with experimental light-curing resins. Caries Res., 42: 117-124.

21. Torres C R, Rosa P C, Ferreira N S, Borges A B (2012): Effect of caries infiltration technique and fluoride therapy on microhardness of enamel carious lesions. Operative Dentistry, 37(4):363-9.

22. Cozza P, Martucci L, De Toffol L, Penco SI (2006): Shear bond strength of metal brackets on enamel. Angle Orthod., 76: 851-856. [Abstract]

23. Ortendahl TW, Thilander B (1998): Use of glass-ionomers for bracket bonding — an ex vivo study evaluating a testing device for in vivo purposes. Eur J Orthod., 20: 201-208.

24. Diedrich P (2000) Praxis der Zahnheilkunde Bracket-Adhäsivtechnik. Munich, Germany: Urban und Fischer Verlag, 170-188.

25. Naidu E, Stawarczyk B, Tawakoli P N, Attin R, Attin TH and Wiegand A (2013 Mar): Shear bond strength of orthodontic resins after caries infiltrant preconditioning. Angle Orthod., 83(2):306-12.

26. Wiegand A, Stawarczyk B, Kolakovic M, Hlammerle CHF, Attin T, Schmidlin PR (2011): Adhesive performance of a caries infiltrant on sound and demineralised enamel. Journal of Dentistry, 39: 117-121.

27. Tang AT, Bjorkman L, Adamczak E, Andlin-Sobocki A, Ekstrand J (2000): In vitro shear bond strength of orthodontic bondings without liquid resin. Acta Odontol Scand., 58: 44-48.

28. Jia L, Stawarczyk B, Schmidlin PR, Attin T, Wiegand A (2012): Effect of caries infiltrant application on shear bond strength of different adhesive systems to sound and demineralized enamel. J Adhes Dent., 14: 569-574.

29. Mews L, Kern M, Ciesielski R, Fischer-Brandies H, Koos B (2015): Shear bond strength of orthodontic brackets to enamel after application of a caries infiltrant. Angle Orthodontist, 85(4):645-650. 